\title{
Towards the Determination of Surface Energy at the Nanoscale: A Further Assessment of the AFM-Based Approach
}

\author{
Dimitrios A. Lamprou ${ }^{1}$, James R. Smith ${ }^{1}$, Thomas G. Nevell ${ }^{1}$, Eugen Barbu ${ }^{1}$, \\ Colin R. Willis ${ }^{2}$, and John Tsibouklis ${ }^{1, *}$ \\ ${ }^{1}$ Biomaterials and Drug Delivery Group, School of Pharmacy and Biomedical Sciences, \\ University of Portsmouth, St. Michael's Building, White Swan Road, Portsmouth P01 2DT, UK \\ 2 Physical Sciences Department, Dstl Porton Down, Salisbury SP4 OJQ, UK
}

\begin{abstract}
Towards the validation of the atomic force microscopy-based approach to the determination of surface energy at the nanometer scale, this paper explores the applicability of the technique by comparing atomic force microscopy-derived surface energy values with those from conventional contact angle measurements from a range of self-assembled organosilane structures ((3-aminopropyl)triethoxysilane, (3-glycidoxypropyl)trimethoxysilane, 3-(triethoxysilyl)propylsuccinic anhydride and trimethoxy(propyl)silane) and also from films of an ultra-low-surface-energy polymer, poly $(1 \mathrm{H}, 1 \mathrm{H}, 2 \mathrm{H}, 2 \mathrm{H}$-perfluorodecyl methacrylate). The close agreement between the two sets of data indicates the validity of the AFM method, while unique attributes are indicated by the high resolution (ca. 1000 atoms) that is inherent to the approach and by the capability to study materials that are not compatible with the probing liquids used for goniometric determinations.
\end{abstract}

Keywords: Surface Energy, Atomic Force Microscopy, Organosilanes, Goniometry.

\section{INTRODUCTION}

Surface energy $\left(\gamma ; \gamma_{\mathrm{S}}\right)$, a measure of the mutual affinity of interacting surfaces, ${ }^{1-3}$ is of key importance in applications that are as diverse as bioadhesion, adsorption and catalysis. ${ }^{4-7}$ This parameter is normally determined from liquid-on-solid contact angle measurements $(\theta$, the internal angle of a tangent drawn at the boundary between a liquid droplet in contact with a solid surface; contact angle goniometry, CAG) ${ }^{8-11}$ that demand the use of liquids that do not penetrate the surface; resolution is limited by the size of the droplet and by surface roughness.

Recent work has detailed the first comparative study of the atomic force microscopy (AFM) and CAG methods for determining $\gamma .{ }^{12}$ The AFM technique has been used to probe, in air, well defined alkanethiol self-assembled structures that had been attached to cleaned, gold-coated AFM tips and substrates. ${ }^{13-14}$ For all alkanethiol self-assembled structures considered, values of interfacial energy $\left(\gamma_{\mathrm{TM}}\right)$ were found to be in close agreement with those from CAG measurements. Towards the assessment of the breadth of the applicability of the technique, this paper compares the

*Author to whom correspondence should be addressed
AFM-determined $\gamma$ values of a range of organosilane multilayer structures ${ }^{15-17}$ and also of a dip-coated polymeric film with those from CAG experiments.

\section{MATERIALS AND METHODS}

\subsection{Preparation of Glass Substrates and AFM Cantilevers}

Glass microscope slides (Agar Scientific, Essex, UK; $1 \mathrm{~mm}$ thick) were cut into $1.25 \mathrm{~cm} \times 1.25 \mathrm{~cm}$ coupons and cleaned using Piranha Solution (3:1 concentrated sulphuric acid, 33\% (v/v): 30\% hydrogen peroxide; Fisher Scientific, Loughborough, UK) for $30 \mathrm{~min} .{ }^{18}$ AFM cantilevers (silicon nitride, NP-20 'C' V-shaped cantilevers; Veeco Instruments SAS, Dourdan, France) and clean substrates were rinsed (water, Millipore, $16.5 \mathrm{M} \Omega \mathrm{cm}$ ) and dried (nitrogen) (Piranha Solution was found to damage AFM cantilevers) ${ }^{13}$

\subsection{Silanisation of Glass Substrates and AFM Cantilevers}

Organosilanes, (3-Aminopropyl)triethoxysilane (APTES, 99\%, $\mathrm{NH}_{2}$-terminated; Acros Organics, Geel, Belgium), 
(3-glycidoxypropyl)trimethoxysilane (GPTMS, 97\%, epoxy-terminated; Alfa Aesar, Heysham, UK), 3-(triethoxysilyl) propylsuccinic anhydride (TESPSA, 95\%, $\mathrm{CO}_{2} \mathrm{H}$-terminated; Wacker-Chemie $\mathrm{GmbH}$, Burghausen, Germany) and trimethoxy(propyl)silane (TPS, 98+\%, $\mathrm{CH}_{3}$-terminated; Alfa Aesar, Heysham, UK), Figure 1, were grafted onto AFM cantilevers and onto cleaned glass surfaces by immersion into a solution of the silane (APTES, $5 \%(\mathrm{v} / \mathrm{v})$; TESPSA, $10 \%(\mathrm{v} / \mathrm{v})$; TPS, $20 \%(\mathrm{v} / \mathrm{v})$; GPTMS, $20 \%(\mathrm{v} / \mathrm{v}))$ in toluene $(99 \%$; Fisher Scientific, Loughborough, UK). ${ }^{17}$ The effect of immersion time on surface energy was investigated at specified time intervals over a period of $32 \mathrm{~h}$. To promote surface relaxation in silane structures and to remove physisorbed multilayers, ${ }^{17,19}$ silanised glass surfaces were subjected to sequential sonications in toluene, N,N-dimethylformamide (DMF, 99\%; Sigma, Steinheim, Germany) and ultrapure water (20 min each), and dried (nitrogen) before use. Prior to sonication, and irrespective of chemical structure, CAG-determined surface energies of organosilanes on glass $\left(16 \mathrm{~h}\right.$ immersion) were $54 \pm 3 \mathrm{~mJ} \mathrm{~m}^{-2}$; those on Piranha-cleaned glass were $43 \pm 2 \mathrm{~mJ} \mathrm{~m}^{-2}$.

\subsection{Polymer-Coated Surfaces and AFM Cantilevers}

Gold-coated glass microscope slides (Au.1000.ALSI, Platypus Technologies, Madison, Wisconsin, USA, cut to $1.25 \mathrm{~cm} \times 1.25 \mathrm{~cm}$ ) and gold-coated AFM cantilevers (NPG-20 'C' V-shaped cantilevers; Veeco Instruments SAS, Dourdan, France) were cleaned by immersion in Gold Surface Cleaning solution (thiourea 1\% (w/v) in $10 \%$ aqueous sulphuric acid; Sigma-Aldrich, Poole, $\mathrm{UK} ; 1 \mathrm{~h}$ and $5 \mathrm{~min}$, respectively), rinsed (water, Millipore, $16.5 \mathrm{M} \Omega \mathrm{cm}$ ) and dried (nitrogen). ${ }^{13}$ Immediately after cleaning, gold-coated substrates and cantilevers, and glass substrates and silicon nitride cantilevers were immersed in poly $(1 \mathrm{H}, 1 \mathrm{H}, 2 \mathrm{H}, 2 \mathrm{H}$-perfluorodecyl methacrylate) (PFDMA; 5\% in 1,1,2-trichlorotrifluoroethane, $99.8 \%$, Aldrich, Dorset, UK) $)^{20}$ for $1 \mathrm{~min}$.

\subsection{Contact Angle and Surface Energies}

To probe liquid-surface interactions at maximal resolution, contact angles $\left(\theta\right.$ at $\left.20^{\circ} \mathrm{C}\right)$ of small drops $(\times 4$ on each substrate) of diiodomethane ('DIM', $>99 \%$, surface tension $\gamma_{\mathrm{L}}=48.7 \mathrm{mN} \mathrm{m}^{-1}$ at $18.8{ }^{\circ} \mathrm{C}$, lit. ${ }^{21}=50.76 \mathrm{mN} \mathrm{m}^{-1}$ at $20{ }^{\circ} \mathrm{C}$; ca.1 $\mu \mathrm{L}$ ) and 1,2-ethanediol (ethylene glycol, 'EG', >99\%; $\gamma_{\mathrm{L}}=47.7 \mathrm{mN} \mathrm{m}^{-1}$ at $18.8{ }^{\circ} \mathrm{C}$, lit. ${ }^{21}=$ $48.40 \mathrm{mN} \mathrm{m}^{-1}$ at $20^{\circ} \mathrm{C}$; ca. $1 \mu \mathrm{L}$ ), Sigma-Aldrich, Poole, $\mathrm{UK}$, and water ('FW', filtered, $\gamma_{\mathrm{L}}=73.4 \mathrm{mN} \mathrm{m}^{-1}$ at $18.8{ }^{\circ} \mathrm{C}$, lit. ${ }^{21}=73.05 \mathrm{mN} \mathrm{m}{ }^{-1}$ at $18.0{ }^{\circ} \mathrm{C}$; ca. $2 \mu \mathrm{L}$; $\mathrm{pH}=5.6)$ placed on horizontal substrates $(\times 2)$ were measured using a goniometer with an enclosed thermostated cell (Kruss G10, Hamburg, Germany). Advancing $\left(\theta_{\mathrm{A}}\right)$ and receding $\left(\theta_{\mathrm{R}}\right)$ angles $\left( \pm 0.1^{\circ}\right.$; with syringe needle removed to enable curve fitting of drop-shape image) were obtained for both 'left' and 'right' contact angles at 20-30 s after placement of the drop. ${ }^{4}$ Surface energies of substrates $\left(\gamma_{s}\right)$ were calculated from the contact angles and the interfacial energies $\left(\gamma_{1}\right)$ of the three probe liquids from Eqs. (1), (2) ${ }^{22,23}$ using a Visual Basic program (University of Portsmouth).

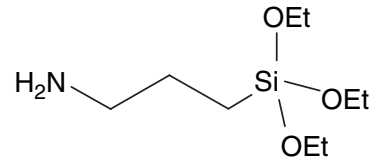

(a)

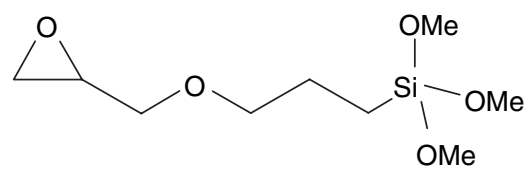

(b)

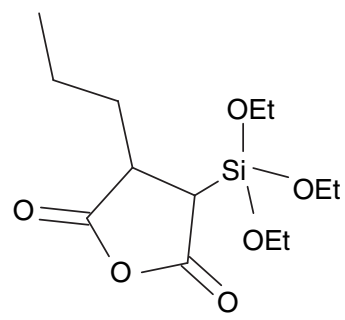

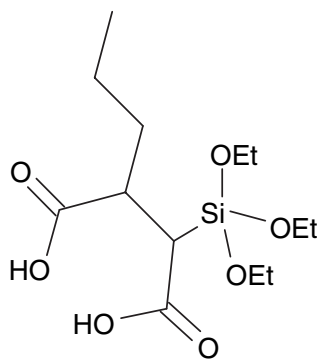

(c)

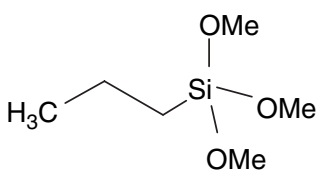

(d)

Fig. 1. (a) (3-Aminopropyl)triethoxysilane (APTES), (b) (3-glycidoxypropyl)trimethoxysilane (GPTMS), (c) 3-(triethoxysilyl)propylsuccinic anhydride (TESPSA) and hydrolysis product, and (d) trimethoxy(propyl)silane (TPS). 


$$
\begin{array}{r}
\gamma_{s}=\gamma_{s}^{\mathrm{LW}}+\gamma_{s}^{\mathrm{AB}}=\gamma_{s}^{\mathrm{LW}}+2\left(\gamma_{s}^{+} \gamma_{s}^{-}\right)^{0.5} \\
\gamma_{l}=\gamma_{l}^{\mathrm{LW}}+\gamma_{l}^{\mathrm{AB}}=\gamma_{l}^{\mathrm{LW}}+2\left(\gamma_{l}^{+} \gamma_{l}^{-}\right)^{0.5} \\
\gamma_{l}(1+\cos \theta) \\
=2\left[\left(\gamma_{s}^{\mathrm{LW}} \gamma_{l}^{\mathrm{LW}}\right)^{0.5}+\left(\gamma_{s}^{+} \gamma_{l}^{-}\right)^{0.5}+\left(\gamma_{s}^{-} \gamma_{l}^{+}\right)^{0.5}\right]
\end{array}
$$

where superscripts denote components of surface energy: Lifshitz-van der Waals LW, acid-base AB, Lewis acid $\gamma^{+}$ and Lewis base $\gamma^{-}$(in $\mathrm{mJ} \mathrm{m}^{-2}$ : FW, $\gamma_{l}^{\mathrm{LW}}=21.8, \gamma_{l}^{+}=$ $\gamma_{l}^{-}=25.5$; DIM, $\gamma_{l}^{\mathrm{LW}}=50.8, \gamma_{l}^{+}=\gamma_{l}^{-}=0$; EG, $\gamma_{l}^{\mathrm{LW}}=29$, $\left.\gamma_{l}^{+}=1.92, \gamma_{l}^{-}=47\right){ }^{24}$

Water contact angles of silanised surfaces were also measured at $\mathrm{pH} 2.5\left(0.1 \mathrm{~mol} \mathrm{dm}^{-3}\right.$ potassium hydrogen phthalate $(100 \mathrm{~mL})$ in $\left.0.1 \mathrm{~mol} \mathrm{dm}{ }^{-3} \mathrm{HCl}(77.6 \mathrm{~mL})\right)$, pH $7.5\left(0.1 \mathrm{~mol} \mathrm{dm}^{-3} \mathrm{KH}_{2} \mathrm{PO}_{4}(100 \mathrm{~mL})\right.$ in $0.1 \mathrm{~mol} \mathrm{dm}^{-3}$ $\mathrm{NaOH}(82.2 \mathrm{~mL}))$, and $\mathrm{pH} 12.5\left(0.2 \mathrm{~mol} \mathrm{dm}^{-3} \mathrm{KCl}\right.$ $(50 \mathrm{~mL})$ in $\left.0.2 \mathrm{~mol} \mathrm{dm}^{-3} \mathrm{NaOH}(40.8 \mathrm{~mL})\right)$, to investigate the effects of $\mathrm{pH}$ on $\theta$.

\subsection{Atomic Force Microscopy}

A MultiMode/NanoScope IV Scanning Probe Microscope (Digital Instruments, Santa Barbara, CA, USA; Veeco software Version 6.11r1) was used for AFM measurements in air (temperature $22 \pm 1{ }^{\circ} \mathrm{C}$; relative humidity $40 \pm 2 \%$ and $55 \pm 1 \%$ for the silanes and polymers, respectively). Force versus distance plots were obtained using silicon nitride probes (NP-20 ' $\mathrm{C}$ ' V-shaped cantilevers; nominal length $\left(l_{\text {nom }}\right)=115 \mu \mathrm{m}$, width $\left(w_{\text {nom }}\right.$, measured perpendicular to long axis $)=17 \mu \mathrm{m}$, resonant frequency $\left(v_{\text {nom }}\right)=56 \mathrm{kHz}$, spring constant $\left(k_{\text {nom }}\right)=$ $0.32 \mathrm{~N} \mathrm{~m}^{-1}$; Veeco Instruments SAS, Dourdan, France) and the J-scanner (maximum $x y z$-translation $=200 \times 200 \times$ $16 \mu \mathrm{m}^{3}$ ). The laser alignment was unaltered during measurements (deflection sensitivity $=65 \pm 15 \mathrm{~nm} \mathrm{~V}^{-1}$ ) and arrays of $10 \times 10$ force-curves (lateral separation, $100 \pm$ $5 \mathrm{~nm}$; ramp size, $800 \mathrm{~nm}$; scan rate, $1.03 \mathrm{~Hz}$ ) were produced from ten different areas $(1000 \mathrm{~nm} \times 1000 \mathrm{~nm}$, separated by $1000 \mathrm{~nm}$ ) on each surface. Measurements were repeated twice using silane surfaces that had been formed sequentially onto glass substrates and $F_{\text {ad }}$ values were extracted from force curve data using an in-housedeveloped Visual Basic program. An accurate value of $k$ (Eq. $(3)^{25}$ ) was obtained from measurements by scanning electron microscopy (JSM-6060LV, JEOL Ltd, Japan; 10 and $25 \mathrm{keV}, 35 \mu \mathrm{m}$ spotsize, working distance 12 $14 \mathrm{~mm}$ ) of the thickness $t$, length $l$ and width $w$ of the cantilever (Effective Young's modulus $E=175 \mathrm{GPa})^{26}$, Table I.

$$
k=\frac{E t^{2} w}{2 l^{2}}
$$

$F_{\text {ad }}$ is related to the work of adhesion $\left(W_{\text {ad }}\right)$ using either the Johnson-Kendall-Roberts (JKR) theory ${ }^{27}$ or DerjaguinMuller-Toporov (DMT) theory ${ }^{28}$, Eq. (4):

$$
\gamma_{\mathrm{SM}}=\gamma_{\mathrm{TM}}=\frac{1}{2} W_{\mathrm{ad}}=\frac{F_{\mathrm{ad}}}{2 c \pi R}
$$

Table I. Measured values of tip radius $R$, cantilever thickness $t$, length $l$, width $w$ and calculated values of $k$ for each cantilever used (Effective Young's modulus $E=175 \mathrm{GPa}$ ). ${ }^{26}$

\begin{tabular}{lcccccc}
\hline $\begin{array}{l}\text { Tip } \\
\text { SD }\end{array}$ & $\begin{array}{c}R / \mathrm{nm} \\
\pm 1\end{array}$ & $\begin{array}{c}l / \mu \mathrm{m} \\
\pm 0.1\end{array}$ & $\begin{array}{c}w / \mu \mathrm{m} \\
\pm 0.1\end{array}$ & $\begin{array}{c}t / \mu \mathrm{m} \\
\pm 0.02\end{array}$ & $\begin{array}{c}v / \mathrm{kHz} \\
\pm 0.5\end{array}$ & $\begin{array}{c}k / \mathrm{N} \mathrm{m}^{-1} \\
\pm 0.02\end{array}$ \\
\hline Silicon nitride & 89 & 97.5 & 17.1 & 0.58 & 55.0 & 0.31 \\
TESPSA & 75 & 110.2 & 18.2 & 0.58 & 60.0 & 0.26 \\
GPTMS & 78 & 112.9 & 18.9 & 0.59 & 52.4 & 0.25 \\
APTES & 77 & 111.9 & 17.2 & 0.58 & 48.4 & 0.23 \\
TPS & 90 & 115.7 & 18.9 & 0.58 & 49.0 & 0.23 \\
PFDMA (NP) & 80 & 111.9 & 19.9 & 0.58 & 61.1 & 0.24 \\
PFDMA (NPG) & 76 & 108.5 & 16.5 & 0.58 & 65.5 & 0.22 \\
\hline
\end{tabular}

where $c=1.5$ and 2 respectively for JKR and DMT models, and $\gamma_{\mathrm{SM}}$ and $\gamma_{\mathrm{TM}}$ are interfacial energies.

The tip radius $(R)$ for each AFM tip was determined by scanning, in contact mode (scan size $4 \mu \mathrm{m}$, scan rate $1.03 \mathrm{~Hz}$ ), an etched silicon surface that possessed features that were sharper than $R$ (TGT01; MikroMasch, San Jose, CA, USA). The radius of curvature was determined by drawing a line-profile across a tip artefact and exporting the height versus width data into an in-house Visual Basic program that allowed the manual fitting of a circle to the tip shape. Surface roughness $\left(R_{\mathrm{a}}\right)$ was determined by entering surface scanning data (contact mode, $\mathrm{NP}-20$ ' $\mathrm{C}$ ' cantilever; 2 areas on 2 reformed surfaces, scan size $=5 \mu \mathrm{m}$, scan rate $=1 \mathrm{~Hz}$ ) into a digitableveling algorithm (Veeco Image Analysis software V 7.10)

\section{RESULTS AND DISCUSSION}

\subsection{Organosilanes Deposited onto Glass}

To determine the optimum immersion time required for organosilane coverage, $\gamma_{\mathrm{s}}$ (CAG) was monitored for glass surfaces that had been exposed to silane solutions $(5-20 \% \mathrm{v} / \mathrm{v}$ in toluene) for specified periods $(1-32 \mathrm{~h}$, Fig. 2). Surface energy values corresponded with those expected on the basis of the chemical nature of the terminal groups: $\mathrm{CO}_{2} \mathrm{H}>$ epoxy $>\mathrm{NH}_{2}>\mathrm{CH}_{3}$ (GPTMS $>$ TESPSA > APTES > TPS; Fig. 2); and, water contact angles (Table II) agreed broadly with literature values for silanes on $\mathrm{Si}$ wafers (TESPSA, $27.2 \pm 5.1^{\circ} ;^{19}$ GPTMS, $44.3 \pm 1.6^{\circ}{ }^{19}$ and $52^{\circ}, 2^{29}$ APTES, $41.6 \pm 2.8^{\circ}{ }^{19}$ and $60^{\circ} ; 3^{30}$ TPS, $\left.82.4^{\circ}\right) .^{31}$ Since for all silane structures $\gamma_{\mathrm{s}}$ values had been found to be reproducible for samples that had been immersed in the parent solution for $16 \mathrm{~h}$, the immersion time for all silanisation reactions was set at $16 \mathrm{~h}$.

Since silanes on glass are more stable than corresponding alkanethiol SAMs on gold, it has been proposed that they are more suitable for uses as biomedical materials. ${ }^{32}$ To assess the effects of $\mathrm{pH}$ variation on the surface energy of implantable silane structures, $\theta_{\mathrm{A}}$ and hysteresis 


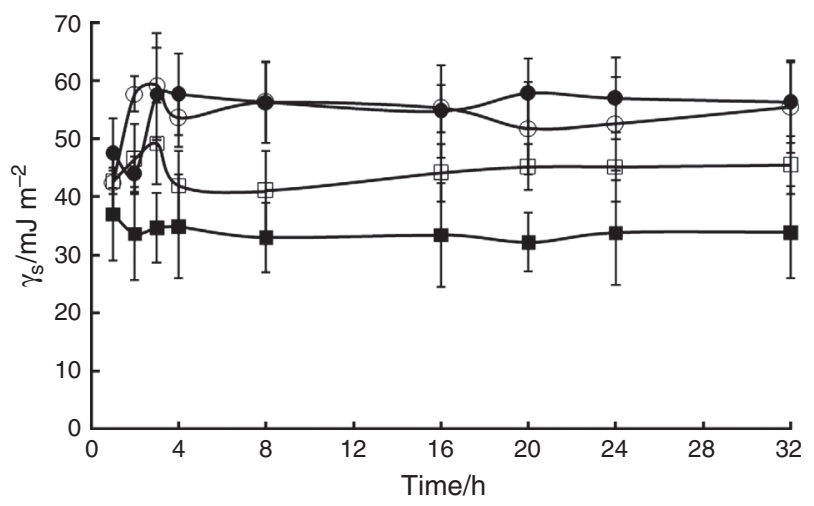

Fig. 2. Surface energies $\left(\gamma_{\mathrm{s}}\right)$ as calculated from advancing $\left(\theta_{\mathrm{A}}\right)$ and receding $\left(\theta_{\mathrm{R}}\right)$ average contact angles on organosilanes grown on glass following different immersion times $\left(n=2 ; T=22{ }^{\circ} \mathrm{C}\right)$ : $(0)=$ TESPSA, $(\bullet)=$ GPTMS, $(\square)=$ APTES, $(\boldsymbol{\square})=$ TPS.

$\left(\theta_{\text {Hys }}\right)$ values of silane-functionalised glass substrates have been measured at three biologically relevant $\mathrm{pHs}$, namely: pH 2.5, 7.5 and 12.5 (Table II).

The $\theta_{\mathrm{A}}$ of the glass surface (control) was seen to decrease with increasing $\mathrm{pH}$; the low $\theta_{\mathrm{Hys}}$ values are consistent with a surface that is flat and homogeneous, as expected. Glass is similar to amorphous silica, in that silanol group coverage has been estimated at $c a .4 .5 \mathrm{SiOH}$ groups $\mathrm{nm}^{-2} .{ }^{33}$ These groups become either positively or negatively charged, depending on $\mathrm{pH}$ (point of zero charge $=\mathrm{pH} 2-3 ;^{34,35} \mathrm{pK}_{\mathrm{a}}(\mathrm{SiOH}$ groups $\left.)=5 \mathbb{F}^{36,37}\right)$, explaining the effect of $\mathrm{pH}$ on $\theta_{\mathrm{A}}$.

For the TESPSA surface, $\theta_{\mathrm{A}}$ increased with increasing $\mathrm{pH}$ (from $33 \pm 3^{\circ}$ to $46 \pm 1^{\circ}$ for $\mathrm{pH} 2.5$ and $\mathrm{pH} 7.5$ ) but at $\mathrm{pH} 12.5 \theta_{\mathrm{A}}$ dropped to below the measurable limit of our instrument $\left(\theta<15^{\circ}\right)$, as expected and in accord with the based catalysed hydrolysis of the ester anhydride functionality and the possible deprotonation of the resulting dicarboxylic acid structure. This behaviour is consistent with observations on the variation of $\mathrm{pH}$ on a carboxylic acid-terminated polyethylene surface. ${ }^{38}$ GPTMS exhibited only a small pH-dependent reduction in $\theta_{\mathrm{A}}$, which is

Table II. Water advancing $\left(\theta_{\mathrm{A}}\right)$ and receding $\left(\theta_{\mathrm{R}}\right)$ contact angles, and hysteresis $\left(\theta_{\mathrm{Hys}}\right)$ values of silanated glass at different $\mathrm{pH}(2.5$, 7.5 and 12.5); $n=8$ (4 droplets on each of duplicate substrates); $16 \mathrm{~h}$.

\begin{tabular}{|c|c|c|c|c|c|c|c|c|c|}
\hline \multirow[b]{3}{*}{ Surface } & \multicolumn{9}{|c|}{ Water contact angles, $\theta /^{\circ}$} \\
\hline & \multicolumn{3}{|c|}{ pH 2.5} & \multicolumn{3}{|c|}{ pH 7.5} & \multicolumn{3}{|c|}{$\mathrm{pH} 12.5$} \\
\hline & $\theta_{\mathrm{A}}$ & $\theta_{\mathrm{R}}$ & $\theta_{\text {Hys }}$ & $\theta_{\mathrm{A}}$ & $\theta_{\mathrm{R}}$ & $\theta_{\text {Hys }}$ & $\theta_{\mathrm{A}}$ & $\theta_{\mathrm{R}}$ & $\theta_{\mathrm{Hy}}$ \\
\hline Glass & $47 \pm 4$ & $45 \pm 5$ & 2 & $38 \pm 5$ & $33 \pm 2$ & 5 & $29 \pm 1$ & $27 \pm 1$ & 2 \\
\hline TESPSA & $33 \pm 3$ & $32 \pm 2$ & 1 & $46 \pm 1$ & $40 \pm 1$ & 6 & - $^{*}$ & - $^{*}$ & - \\
\hline GPTMS & $44 \pm 1$ & $42 \pm 1$ & 2 & $38 \pm 3$ & $32 \pm 4$ & 6 & $34 \pm 4$ & $27 \pm 2$ & 7 \\
\hline APTES & $36 \pm 4$ & $29 \pm 1$ & 7 & $37 \pm 3$ & $26 \pm 2$ & 11 & - $^{*}$ & - $^{*}$ & - \\
\hline TPS & $79 \pm 4$ & $76 \pm 3$ & 3 & $81 \pm 3$ & $79 \pm 3$ & 2 & $77 \pm 5$ & $75 \pm 5$ & 2 \\
\hline
\end{tabular}

${ }^{*} \theta<15^{\circ}$ (could not be measured with the available instrument). consistent with the expected Lewis base behaviour of the epoxide ring structure; the increase in $\theta_{\text {Hys }}$ with increasing $\mathrm{pH}$ must however reflect some protonation-induced surface modification. Consistent with the acid-induced quaternisation of the amino functionality, APTES exhibited similar $\theta_{\mathrm{A}}$ values $\left(36 \pm 4^{\circ}\right.$ and $\left.37 \pm 4^{\circ}\right)$ at $\mathrm{pH} 2.5$ and 7.5 , but $\theta_{\mathrm{A}}$ decreased to $<15^{\circ}$ at $\mathrm{pH} 12.5$; APTES is positively charged up to $\mathrm{pH} 10.2$, the $\mathrm{pK}_{\mathrm{a}}$ value of the conjugate acid, ${ }^{39}$ but above this $\mathrm{pH}$ value the amphoteric amine functionality becomes a proton donor allowing the surface to acquire a negative charge which in turn accounts for the low $\theta_{\mathrm{A}}$ value. Large $\theta_{\mathrm{Hys}}$ values associated with this surface are reflective of considerable heterogeneity: it is known that only $30-50 \%$ of silanol groups are grafted during silanisation. ${ }^{40}$ As expected, the $\theta_{\mathrm{A}}$ and $\theta_{\mathrm{Hys}}$ values characterising the relatively inert TPS surface were little affected by $\mathrm{pH}$.

With the exception of TPS structures, the $F_{\text {ad }}$ values characterising the interaction between each of the silanised glass substrates and an uncoated silicon nitride tip were similar (ca. $90 \mathrm{nN}$ vs. ca. $40 \mathrm{nN}$ for TPS; Fig. 3), with the implication that these values must reflect the combined effects of the polarity of the silanised layer and the extent of hydrogen bonded interactions between the interacting surfaces. ${ }^{41}$ The $F_{\text {ad }}$ values for the silanes are less differentiated than $\gamma_{\mathrm{s}}$ values obtained from CAG (Fig. 2).

16 Using similarly silanised AFM tips and substrate surfaces, $\gamma_{\mathrm{TM}}$ values were obtained from $W_{\text {ad }}$ measurements (Eq. (4), Table III). TESPSA and GPTMS had relatively high values (JKR: $52 \pm 3 \mathrm{~mJ} \mathrm{~m}^{-2}$ and $50 \pm 3 \mathrm{~mJ} \mathrm{~m}^{-2}$, respectively), as expected due to their high polarity. The lower $\gamma_{\mathrm{TM}}$ for APTES (JKR: $41 \pm 3 \mathrm{~mJ} \mathrm{~m}^{-2}$ ) may be due to the presentation of methylene groups into the surface or due to interactions of the $\mathrm{NH}_{2}$ groups with the glass/polar silane matrix. ${ }^{30,42-44}$ TPS exhibited a similar $\gamma_{\mathrm{TM}}$ value that was higher than that expected for a hydrophobic tail group, as assessed by comparing the determined value

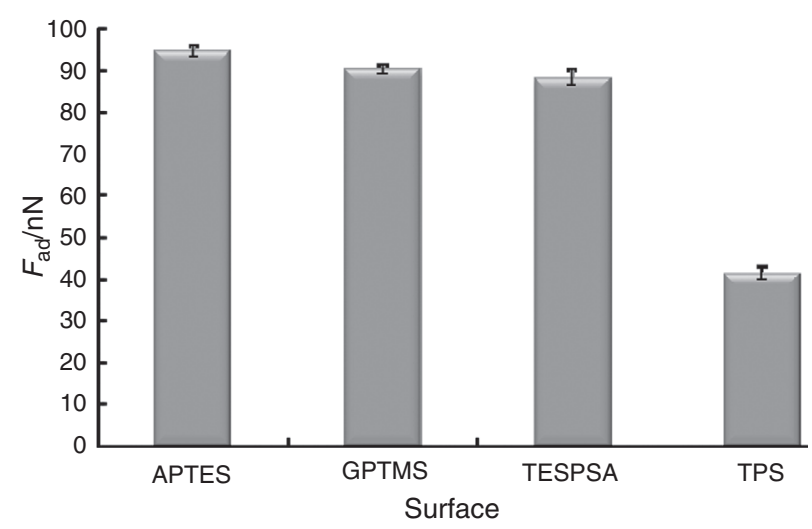

Fig. 3. Force of adhesion $\left(F_{\text {ad }}\right)$ values for the interaction between a silicon nitride AFM tip and each organosilane (air; $n=2 ; 16 \mathrm{~h}$ ). 
Table III. Determined values of $F_{\text {ad }}, W_{\text {ad }}$ and $R_{\mathrm{a}}$ for organosilane-coated glass substrates and tips $\left(T=22 \pm 1{ }^{\circ} \mathrm{C}, R H=40 \pm 2 \% ; 10\right.$ areas, $10 \times 10$ force measurements for each), and corresponding surface energies, $\gamma_{\mathrm{TM}}$, from JKR and from DMT calculations.

\begin{tabular}{lcccccc}
\hline System & $F_{\text {ad }} / \mathrm{nN}$ & $R_{\mathrm{a}} / \mathrm{nm}$ & $W_{\text {ad }}(\mathrm{JKR}) / \mathrm{mJ} \mathrm{m}^{-2}$ & $W_{\text {ad }}(\mathrm{DMT}) / \mathrm{mJ} \mathrm{m}^{-2}$ & $\gamma_{\mathrm{TM}}(\mathrm{JKR}) / \mathrm{mJ} \mathrm{m}^{-2}$ & $\gamma_{\mathrm{TM}}(\mathrm{DMT}) / \mathrm{mJ} \mathrm{m}^{-2}$ \\
\hline TESPSA-TESPSA & $36 \pm 2$ & 1.5 & $103 \pm 7$ & $77 \pm 5$ & $52 \pm 3$ & $50 \pm 3$ \\
GPTMS-GPTMS & $37 \pm 2$ & 2.7 & $99 \pm 5$ & $81 \pm 6$ & $61 \pm 4$ & $41 \pm 3$ \\
APTES-APTES & $30 \pm 2$ & 0.8 & $87 \pm 4$ & $66 \pm 3$ & $43 \pm 3$ & $37 \pm 2$ \\
TPS-TPS & $38 \pm 2$ & 0.9 & & $33 \pm 2$ \\
\hline
\end{tabular}

with that seen for corresponding 1-undecanethiol SAM-tip interactions on gold (JKR: $32 \pm 3 \mathrm{~mJ} \mathrm{~m}^{-2}$ ). ${ }^{12}$ This may be explained in terms of the inefficiency of the relatively short hydrophobic chains $\left(\mathrm{C}_{3}\right)$ to mask the influence of the extensive polar silane matrix and/or in terms of the increased disorder in multilayered films. The $\gamma_{S}$ values obtained from $\theta_{\mathrm{A}}$ and $\theta_{\mathrm{R}}(\mathrm{CAG})$ measurements are in close agreement with $\gamma_{\mathrm{TM}}(\mathrm{JKR})$ values from AFM experiments (Fig. 4) but, with the exception of the more non-polar silane structure, $\gamma_{\mathrm{TM}}(\mathrm{DMT})$ values are significantly lower (Fig. 4).

\subsection{Poly(1H,1H,2H,2H-Perfluorodecyl Methacrylate)}

The $\gamma_{\mathrm{s}}$ of PFDMA has been evaluated at $12.7 \pm 0.7 \mathrm{~mJ} \mathrm{~m}^{-2}$ (JKR) or at $9.5 \pm 0.6 \mathrm{~mJ} \mathrm{~m}^{-2}$ (DMT) using both goldcoated AFM tips (NPG) and glass surfaces and at $7.9 \pm$ $0.5 \mathrm{~mJ} \mathrm{~m}^{-2}$ (JKR) or at $5.9 \pm 0.4 \mathrm{~mJ} \mathrm{~m}^{-2} \mathrm{P}(\mathrm{DMT})$ using silicon nitride tips (NP) and glass surfaces. The $\gamma_{\mathrm{TM}}(\mathrm{JKR})$ value determined with the NP-glass system is almost identical to the CAG-determined $\gamma_{\mathrm{s}}$ value for the same polymer on glass $\left(7.5 \pm 0.4 \mathrm{~mJ} \mathrm{~m}^{-2}\right) .{ }^{20}$ Heterogeneous coverage of the polymer over the gold-coated substrate and/or the influence of interactions with the underlying gold may have had some effect on the reported evaluations.

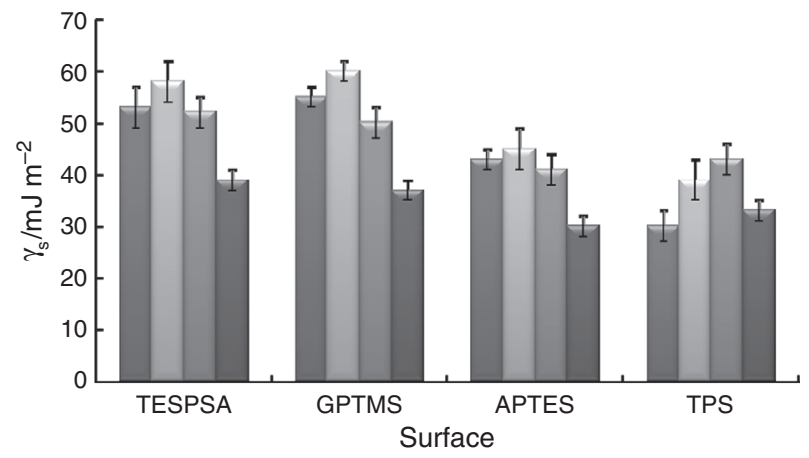

$$
\begin{array}{|ll|}
\hline \gamma_{\mathrm{S}} \text { (CAG, Advancing) } & \gamma_{\mathrm{TM}} \text { (AFM, JKR) } \\
\square \gamma_{\mathrm{S}} \text { (CAG, Receding) } & \gamma_{\mathrm{TM}} \text { (AFM, DMT) } \\
\hline
\end{array}
$$

Fig. 4. Surface energies determined by $\operatorname{CAG}\left(\theta_{\mathrm{A}}\right.$ and $\left.\theta_{\mathrm{R}}\right)$ versus $\mathrm{AFM}$ (JKR and DMT methods; $n=2 ; 16 \mathrm{~h}$ ).

\section{CONCLUSIONS}

The capability of the atomic force microscope as a tool for the determination of surface energy has been demonstrated against a number of functionalised surfaces, providing further evidence that the technique may be universally applicable.

Acknowledgment: We thank the Institute of Biomedical and Biomolecular Sciences (IBBS), University of Portsmouth, for providing a studentship to DL.

\section{References and Notes}

1. W. M. Merrill, A. V. Pocius, B. V. Thakker, and M. Tirrell, $\underline{\text { Langmuir }}$ 7, 1975 (1991).

2. J. C. Hooton, C. S. German, M. C. Davies, and C. J. Roberts, Eur. g. Pharm. Sci. 28, 315 (2006).

3. J. Pacifico, K. Endo, S. Morgan, and P. Mulvaney, J. Am. Chem. Soc. 622, 11072 (2006).

4. A. W. Adamson and A. P. Gast, Physical Chemistry of Surfaces, 6th edn., Wiley-Interscience, New York (1997).

5. M. Graupe, T. Koini, H. I. Kim, N. Garg, Y. F. Miura, M. Takenaga, S. S. Perry, and T. R. Lee, Colloids Surf. 154, 239 (1999).

6. V. J. Morris, A. R. Kirby, and A. P. Gunning, Atomic Force Microscopy for Biologists, Imperial College Press, London (1999).

7. C. I. Pereni, Q. Zhao, Y. Liu, and E. Abel, Colloids Surf. B: Biointerfaces 48, 143 (2006).

8. A. W. Neumann and R. J. Good, Surf. Colloid Sci. 11, 31 (1979).

9. R. G. Good and C. J. van Oss, Modern Approaches to Wettability: Theory and Applications, edited by M. E. Schrader and G. Loeb, Plenum Press, New York (1991), pp. 1-27.

10. A. Amirfazli and A. Neumann, Adv. Colloid Interf. Sci. 110, 121 (2004).

11. T. Blake, J. Colloid Interface Sci. 299, 1 (2006).

12. D. A. Lamprou, J. R. Smith, T. G. Nevell, E. Barbu, C. Stone, C. R. Willis, and J. Tsibouklis, Appl. Surf. Sci. 256, 5082 (2010).

13. D. A. Lamprou, J. R. Smith, T. G. Nevell, E. Barbu, C. R. Willis, and J. Tsibouklis, Appl. Surf. Sci. 256, 1961 (2010).

14. D. A. Lamprou, J. R. Smith, T. G. Nevell, E. Barbu, C. Stone, C. R. Willis, R. J. Ewen, and J. Tsibouklis, Surf. Sci. 604, 540 (2010).

15. P. Silberzan, L. Leger, D. Ausserre, and J. J. Benattar, Langmuir 7, 1647 (1991).

16. A. Ulman, An Introduction to Ultrathin Organic Films: From Langmuir-Blodgett to Self-Assembly, Academic Press, New York (1991).

17. G. K. Toworfe, R. J. Composto, I. M. Shapiro, and P. Ducheyne, Biomaterials 23, 631 (2006).

18. A.-S. Duwez, C. Poleunis, P. Bertrand, and B. Nysten, Langmuir 17, 6351 (2001). 
19. M. H. Lee, D. A. Brass, R. Morris, R. J. Composto, and P. Ducheyne, Biomaterials 26, 1732 (2005).

20. J. Tsibouklis, P. Graham, P. J. Eaton, J. R. Smith, T. G. Nevell, J. D. Smart, and R. J. Ewen, Macromolecules 33, 8460 (2000).

21. G. W. C. Kaye and T. H. Laby, Table of Physical and Chemical Constants, 15th edn., Longman Scientific and Technical, Harlow (1992).

22. W. A. Zisman, Relation of the equilibrium contact angle to liquid and solid constitution, Contact Angle, Wettability, and Adhesion, edited by R. F. Gould, D.C. Advances in Chemistry Series 43, American Chemical Society, Washington (1964), pp. 1-51.

23. J. Long, M. Hyder, R. Huang, and P. Chen, Adv. Colloid Interface Sci. 118, 173 (2005).

24. B. Janczuk, T. Bialopiotrowicz, and A. Zdziennicka, J. Colloid Interface Sci. 221, 96 (1999).

25. W. F. Stokey, Shock and Vibration Handbook, McGraw-Hill, New York (1989).

26. L. L. Hazel and V. V. Tsukruk, Thin Solid Films 339, 246 (1999).

27. K. L. Johnson, K. Kendall, and A. D. Roberts, Proc. R. Soc. London A 324, 301 (1971).

28. B. V. Derjaguin, V. M. Muller, and Y. P. Toporov, J. Colloid Interface Sci. 53, 314 (1975).

29. V. V. Tsukruk, I. Luzinov, and D. Julthongpiput, Langmuir 15, 3029 (1999).

30. P. A. Heiney, K. Grueneberg, J. Fang, C. Dulcey, and R. Shashidhar, Langmuir 16, 2651 (2000).
31. H. Onoe, K. Matsumoto, and I. Shimoyama (eds.), Proc. 16th IEEE Annual Internat. Conf. Micro Electro Mechanical Systems, Kyoto, Japan (2003).

32. A. Kurella and N. B. Dahotre, J. Biomater. Appl. 20, 6 (2005).

33. L. T. Zhuravlev, Colloids Surf. A: Physicochem. Enging. Aspects 74, 71 (1993).

34. G. A. Parks, Chem. Rev. 65, 177 (1965).

35. A. Carré, F. Roger, and C. Varinot, J. Colloid Interface Sci. 154, 174 (1992).

36. M. L. Hair and W. Hertl, J. Phys. Chem. 74, 91 (1970).

37. R. A. Van Wagenen, J. D. Andrade, and J. B. Hibbs, J. Electrochem. Soc. 123,1438 (1976).

38. S. R. Holmes-Farley, R. H. Reamey, T. J. McCarthy, J. Deutch, and G. M. Whitesides, Langmuir 1, 725 (1985).

39. M. Bezanilla, S. Manne, D. E. Laney, Y. L. Lyubchenko, and H. G. Hansma, Langmuir 11, 655 (1995).

40. E. F. Vansant, P. Van der Voort, and K. C. Vranken, Characterization and Chemical Modification of the Silica, Elsevier, Amsterdam (1995).

41. H.-J. Butt, B. Cappella, and M. Kappl, Surf. Sci. Rep. 59, 1 (2005).

42. W. J. Van Ooij and A. Sabata, Silanes and Other Coupling Agents, edited by K. L. Mittal, VSP International Science, The Netherlands (1992), pp. 323-343.

43. K. M. R. Kallury, P. M. Macdonald, and M. Thompson, Langmuir 10, 492 (1994).

44. E. W. Van der Vegte and G. Hadziioannou, Langmuir 13, 4357 $\underline{(1997)}$.

Received: 8 June 2010. Accepted: 16 June 2010. 